Available online on 15.07 .2020 at http://jddtonline.info
Open Access to Pharmaceutical and Medical Research

Open $\odot$ Access

Research Article

\title{
Gastroprotective effect and in vitro Antioxidant Activities of the Aqueous Extract from Artemisia absinthium L Aerial Parts
}

\author{
Chahrazed Kaoudoune*1,2, Fatima Benchikh1, Hassiba Benabdallah¹, Karima Loucif ${ }^{1}$, Soulaf Mehlous, \\ Smain Amira ${ }^{1}$
}

${ }^{1}$ Laboratory of Phytotherapy Applied to Chronic Diseases, Department of Animal Biology and Physiology, Faculty of Nature and Life Sciences, University Ferhat Abbas, Setif-1, 19000, Algeria

${ }^{2}$ Laboratory of Environmental Biosurveillance, Faculty of Sciences, Department of Biology, Badji Mokhtar University, 23000-Annaba, Algeria

\begin{abstract}
Artemisia absinthium $L$. is a medicinal plant largely used in traditional medicine. The aim of this study was to estimate the content of polyphenols, and flavonoids compounds and also to evaluate the antioxidant and the anti-ulcer activities of the Aqueous extract from Artemisia absinthium L. aerial parts. The Folin-Ciocalteau and $\mathrm{AlCl}_{3}$ methods were applied in order to quantify the polyphenolic and flavonoids contents, respectively. However, DPPH method was used to evaluate the in vitro antioxidant activity. Quantitative analysis of the yield and phenolic content of the aqueous extract of Artemisia absinthium showed that the yield of the aqueous extract was $19.32 \%$ and its phenolic content was $58.66 \pm 2.16 \mu \mathrm{g} \mathrm{GAE} / \mathrm{mg}$ dry extract for polyphenols and $6.85 \mu \mathrm{g} \mathrm{QE} \mathrm{/} \mathrm{mg} \mathrm{dry} \mathrm{extract} \mathrm{for} \mathrm{the} \mathrm{flavonoids.} \mathrm{The} \mathrm{antioxidant} \mathrm{activity} \mathrm{of} \mathrm{the} \mathrm{plant}$ extract evaluated by the DPPH test is very important ( $\mathrm{IC}_{50}=45.48 \pm 0.37 \mu \mathrm{g} / \mathrm{ml}$ ). Treatment of mice with the aqueous extract of Artemisia absinthium at a dose of $400 \mathrm{mg} / \mathrm{kg}$ significantly reduced the ulcerogenic effect of ethanol on the gastric wall with an estimated protection rate of 91\%. These findings suggest that Artemisia absinthium L. aqueous extract possessed good antiulcer and antioxidant potentials. This supports the traditional claims of this plant in folklore medicine.
\end{abstract}

Keywords: Artemisia absinthium, polyphenols, antioxidant activity, gastric ulcer, ethanol.

Article Info: Received 21 April 2020; Review Completed 22 June 2020; Accepted 04 July 2020; Available online 15 July 2020

Cite this article as:

Kaoudoune C, Benchikh F, Benabdallah H, Loucif K, Mehlous S, Amira S, Gastroprotective effect and in vitro Antioxidant Activities of the Aqueous Extract from Artemisia absinthium L Aerial Parts, Journal of Drug Delivery and Therapeutics. 2020; 10(4):153-156 http://dx.doi.org/10.22270/jddt.v10i4.4253

*Address for Correspondence:

Chahrazed Kaoudoune, Laboratory of Phytotherapy Applied to Chronic Diseases, Department of Animal Biology and Physiology, Faculty of Nature and Life Sciences, University Ferhat Abbas, Setif-1, 19000, Algeria

\section{INTRODUCTION}

Artemisia absinthium L. (A. absinthium) belonging to the Asteraceae family, commonly known as "wormwood" in United Kingdom, as "absinthe" in France, and as "chajret mariem" in Tunisia has been known since ancient times as having important botanical and pharmaceutical properties ${ }^{1}$.

Artemisia absinthium L is a yellow-flowering perennial plant which grows widely in dry sunny regions of Europe and Siberia, Northern Africa, North and South America and is used for its antiparasitic effects and to treat anorexia and indigestion. The aerial parts are present in many gastric herbal preparations, in dietary supplements, and in alcoholic beverages, for example absinthe products, which are enjoying a resurgence of popularity all over the world 2, 3 . Aerial parts of $A$. absinthium are an easily accessible source of natural antioxidants and antidepressants ${ }^{4}$.
Reactive oxygen species (ROS) and reactive nitrogen species (RNS) are produced continuously in the body via oxidative metabolism, mitochondrial bioenergetics, and immune function 5. The term "oxidative stress" implies that the physiological balance between the creation of ROS and the ability to detoxify these molecules has been upset, leading to resultant stress and damage to cellular systems. Importantly, this can either indicate that there may be an abnormal elevation in ROS generation, or that there may be deficiencies in antioxidant defense systems. While ROS can serve as second messengers, be purposefully weaponized by our immune system to fight pathogens ${ }^{6}$. This oxidative stress is involved in several pathological situations including hypertension, heart failure and diabetes ${ }^{7}$.

Peptic ulcer disease is a multifactorial and complex disease involving gastric and duodenal ulcers. Peptic ulcer results from a pathological condition in which the biological balance between defensive and offensive factors in the 
gastrointestinal tract is disturbed. Gastric hydrochloric acid, pepsin, reactive free radicals and oxidants, leukotriens, refluxed bile, and endothelins are among the main endogenous aggressive factors ${ }^{8}$. Given the interest Artemisia absinthium of in folk medicine, this study aims to assess the polyphenolic contents of the aqueous extract from aerial parts of Artemisia absinthium L and evaluate the in vitro antioxidant and antiulcer activity.

\section{MATERIALS AND METHODS}

\subsection{Plant material}

The aerial parts from Artemisia absinthium were collected from Setif North-Eastern part of Algeria, before the flowering stage. The plant was identified and authenticated by Prof. Laouer H., a botanist at the Department of Biology and Vegetal Ecology, University of Sétif, Algeria. The plant was dried in the shade and grounded into a fine powder using an electric mill.

\subsection{Preparation of extract}

The preparation of the plant extract was done according to the method of 9 . The dried powder of the plant aerial parts ( $50 \mathrm{~g}$ ) was boiled in 500 milliliters of distilled water for 20 minutes with magnetic stirring. The resulting mixture was filtered using Wattman filter paper $\mathrm{N}^{\circ} 1$ and then dried at 45 ${ }^{\circ} \mathrm{C}$. The dried extract thus obtained (AqE) was screened for its pharmacological properties.

\subsection{Animals}

Healthy male Swiss albino mice (Pasteur Institute, Algiers, Algeria), weighing 25-30 g were used. Animals were housed in an air-conditioned animal room (12 hours light/dark cycle, $23 \pm 2^{\circ} \mathrm{C}$ ). All the animals were given food and water ad libitum for a week. Mice were fasted for 18-20 h with free access to water until 1 hour before the start of the experiment. During the fasting period, the animals were placed individually in cages with wide-mesh wire bottoms to prevent coprophagy.

\subsection{Calculation of the plant extraction yield}

The yield of the plant extract it is the ratio between the weight of the extract and the weight of the treated plant. The yield which is expressed as a percentage has been calculated by the following formula:

$\mathrm{Y}=\mathrm{WE} / \mathrm{Wp} \times 100$ where

$\mathrm{Y}=$ Yield of the extract in percentage.

$\mathrm{WE}=$ Weight of the extract in grams.

$\mathrm{Wp}=$ Weight of the plant in grams.

\subsection{Determination of total polyphenols content}

The total polyphenols content was determined by the FolinCiocalteu method as described ${ }^{10}$. A volume of $0.1 \mathrm{ml}$ of plant extract was mixed with $0.5 \mathrm{ml}$ of Folin-Ciocalteu reagent (diluted 10 times). After $4 \mathrm{~min}, 0.4 \mathrm{ml}$ of $7.5 \%$ sodium carbonate $\left(\mathrm{Na}_{2} \mathrm{CO}_{3}\right)$ solution was added. The final mixture was shaken and then incubated for 90 min in dark at room temperature. The absorbance of the samples was measured at $765 \mathrm{~nm}$ and the results are expressed in micrograms of gallic acid equivalents per milligrams of dried weight $(\mu \mathrm{g}$ GAE/mg DW).

\subsection{Determination of total flavonoids content}

The total flavonoids content of each extract was determined by a colorimetric method as described by ${ }^{11}$. A volume of 0.5 $\mathrm{ml}$ of plant extract was mixed with $0.5 \mathrm{ml}$ of aluminum chloride $\left(\mathrm{AlCl}_{3}\right)$ solution $(2 \%)$ and allowed to stand for 10 min. Absorbance of the mixture was then determined at 430 nm versus prepared methanol blank. Results were expressed as quercetin equivalent per milligrams of dried weight $(\mu \mathrm{g}$ $\mathrm{QE} / \mathrm{mg} \mathrm{DW}$ ).

\subsection{Evaluation of in vitro antioxidant activities by DPPH radical scavenging assay}

Free radical scavenging activity against 2, 2-diphenyl- 1picrylhydrazyl (DPPH) radical was measured using the method described by ${ }^{12}$. A volume of $50 \mu \mathrm{l}$ of different dilutions of the AqE extract was added to $1250 \mu \mathrm{l}$ of a $0.004 \%$ methanol solution of DPPH. After $30 \mathrm{~min}$ of incubation at room temperature, the absorbance was measured at $517 \mathrm{~nm}$. BHT and gallic acid were used as standards. Inhibition of free radical DPPH in percent (I \%) was calculated in following way: $\mathrm{I} \%=100$ (A control $-\mathrm{A}$ sample) /A control, where A control is the absorbance of the blank solution (containing all reagents except the test compound), and A sample is the absorbance in the presence of the test compound.

\subsection{Evaluation of ethanol induced acute gastric ulcer in mice}

The test consisted of verifying the protective action of the extracts against the ulcer caused in animals by the administration of an ulcerogenic agent (ethanol) using the method described by 13 .

The animals were divided into 2 groups, consisting of 5 mice each. Each mice in each group was subsequently separately placed in a cage. Group 1 mice were treated with distillated water as negative control. Groups 2 mice were treated with $\mathrm{AqE}$ at dose $400 \mathrm{mg} / \mathrm{kg}$. After 60 minutes of the oral respective treatments $(5 \mathrm{ml} / \mathrm{kg})$, ulceration was induced by intragastric instillation of $70 \%$ ethanol ( $100 \mu \mathrm{l} /$ mice $)$. Thirty minutes later, the animals were sacrificed with cervical dislocation and each stomach was incised along the greater curvature, photographed and macroscopically examined for linear haemorrhagic lesions in the glandular region. The length $(\mathrm{mm})$ of each lesion was determined and each length was summed per stomach. The sum of length $(\mathrm{mm})$ of all lesions for each stomach was used as the ulcer index (UI). The percentage inhibition was calculated by the following formula: \% inhibition $=$ UI control - UI treated $/$ UI control $\times$ 100.

\subsection{Statistical analysis}

The results were represented as the means \pm standard deviation (SD) $(n=3)$. All measurements were conducted in three determinations $(n=3)$. Analysis of variance was done using Student's t-test or one-way analysis of variance (ANOVA) with the aid of Graph Pad Prism 7.00. p values < 0.05 were regarded as significant.

\section{RESULTS AND DISCUSSION}

\subsection{Percentage of extraction yield}

The aqueous extract has a high yield percent (19.32\%) (Table 01). This value is greater than the values calculated by 14, 15. Many studies point out that the percentage of extraction yield depends mainly on the extraction procedure, in particular, the temperature used during the extraction, the polarity of the compounds of the extract, the solvent ratio and the methods of extraction (maceration, decoction, evaporation) 16,17 .

\subsection{Total penolics acid and flavonoids contents}

Polyphenols are defined as secondary metabolites resulting from the shikimate pathway-derived phenylpropanoid and/or the polyketide pathway(s) ${ }^{18}$. Polyphenols have been suggested to exert a plethora of biological activities 
including antioxidant, anti-inflammatory, anti-microbial, anti-proliferative, pro-apoptotic activity and hormonal regulation capacity 19 .

In this study, the total phenolic and flavonoids contents in Artemisia absinthium $L$ aqueous extract were determined and the results are shown in Table 01.

The content of polyphenols and flavonoids in the aqueous extract of Artemisia absinthium is $58.66 \pm 2.16 \mu \mathrm{g}$ equivalent of gallic acid / mg of extract and $6.85 \pm 00 \mu \mathrm{g}$ equivalent of quercetin / mg of dry extract, respectively. These values are lower than those obtained by ${ }^{15}$. On the other hand; the values of the present study are higher than that found by 20 . This difference may be due to the solvent used for the extraction and the dosing method.

It is important to emphasize that the method used (the choice of solvents), as well as the conditions under which the extraction is carried out (hot or cold), affects the total content of phenols and flavonoids, and therefore affects the biological activities mediated by these metabolites ${ }^{21}$. It is well established that the amounts of phenolic compounds and their nature in plants are linked to climatic conditions, altitude and the characteristics of soil 22 .

Table 01: Total phenolics, flavonoids contents and extraction yield of Artemisia absinthium L. areal part aqueous extract (AqE).

\begin{tabular}{|l|l|l|l|}
\hline Extrait & $\begin{array}{l}\text { \% Yield } \\
(\mathrm{W} / \mathrm{W})\end{array}$ & $\begin{array}{l}\text { Total phenolics } \\
(\mu \mathrm{g} \text { GAE/mg DW) }\end{array}$ & $\begin{array}{l}\text { Total flavonoids } \\
(\mu \mathrm{g} \text { EQ } / \mathrm{mg} \mathrm{DW})\end{array}$ \\
\hline $\mathrm{AqE}$ & 19.32 & $58.66 \pm 2.16$ & $6.85 \pm 00$ \\
\hline
\end{tabular}

\subsection{Antioxidant activity}

The DPPH radical is often used as an indicator to test the ability of the extract to give an hydrogen atom or an electron and therefore its anti-radical or antioxidant capacity 23,24 .
The evaluation of antioxidant activity by the DPPH test, revealed an antioxidant power in the aqueous extract with an $\mathrm{IC}_{50}$ of $45.48 \pm 0.37 \mu \mathrm{g} / \mathrm{ml}$ (Table 02 ). The comparison of this activity with the reference antioxidants reveals that gallic acid $\left(\mathrm{IC}_{50}=1.56 \pm 0.091 \mu \mathrm{g} / \mathrm{ml}\right.$ ) is more effective than BHT $\left(\mathrm{IC}_{50}=21.83 \pm 0.20 \mu \mathrm{g} / \mathrm{ml}\right)$. Even the antioxidant activity of the AqE is strong ( $\mathrm{IC}_{50} 45.48 \pm 0.37 \mu \mathrm{g} / \mathrm{ml}$ ), but still lower than both antioxidant references (BHT and gallic acid).

The antioxidant activity of the aqueous extract of Artemisia absinthium is lower than that found by 114,25 . This difference in the antioxidant activity is may be due to the presence of phenolic compounds and the region and season of the plant harvest.

Table 2: DPPH radical scavenging activity of. Artemisia absinthium areal part aqueous extract (AqE).

\begin{tabular}{|c|c|}
\hline \multirow{2}{*}{ Extract/ standard } & DPPH scavenging activity \\
\cline { 2 - 2 } & $\mathrm{IC}_{50}(\mu \mathrm{g} / \mathrm{mL})$ \\
\hline AqE & $45.48 \pm 0.37^{* * * *}$ \\
\hline Gallic acid & $1.56 \pm 0.091$ \\
\hline BHT & $21.83 \pm 0.20$ \\
\hline
\end{tabular}

Data were presented as IC 50 means $\pm \mathrm{SD}\left(\mathrm{n}=3\right.$. $^{* * * *} \mathrm{P}<$ 0.0001 vs BHT and gallic acid

\subsection{Ethanol induced acute gastric ulcer}

\subsubsection{Macroscopic observations}

This study evaluated the degree of protection of the aqueous extract against ulceration of the gastric mucosa caused by ethanol. The mice which received the ulcerogenic agent (ethanol), showed damage on gastric mucosa, large and deep lesions of dark red color with a significant length all along the stomach (Figure 1). Pre-treatment of animals with the plant extract $(400 \mathrm{mg} / \mathrm{kg})$, significantly attenuated injuries caused by ethanol. Small superficial lesions of black-red color are observed, but their lengths are extremely reduced compared to untreated mice.
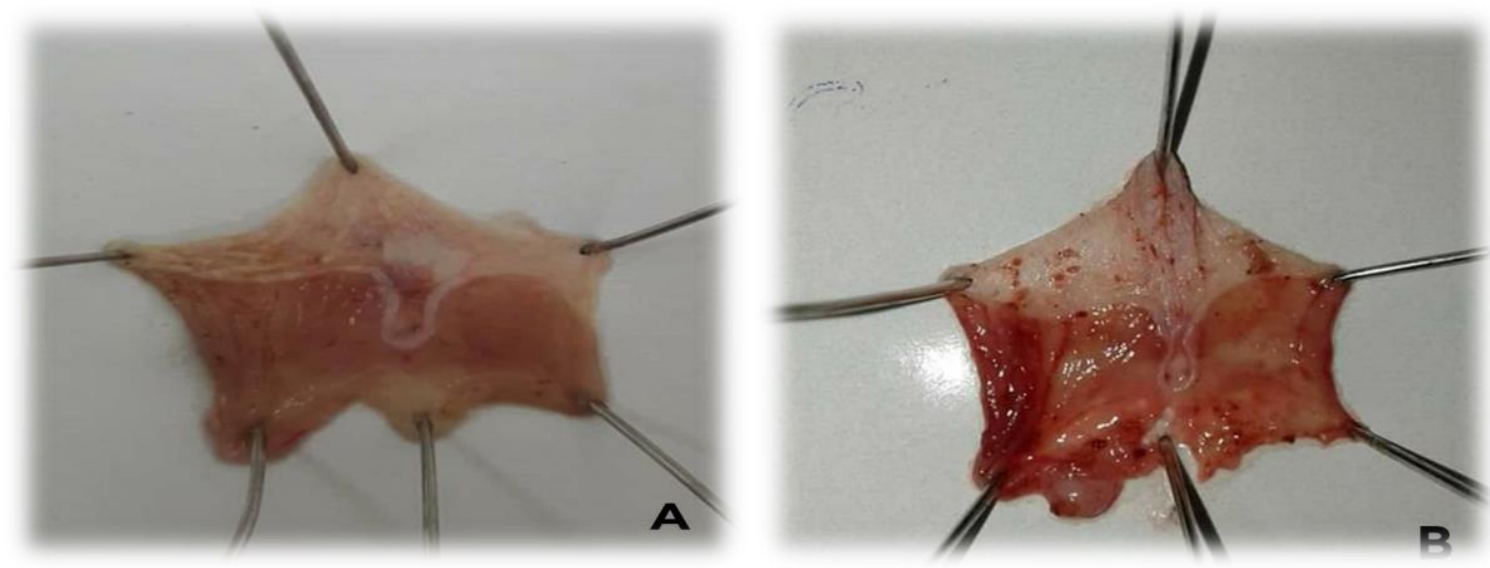

Figure1: Effect of dose of aqueous extract A. absinthium on the severity of gastric lesion examined in ethanol-induced gastric ulceration model in Mice.

A: aqueous extract of $A$. absinthium (400 mg/kg). B: injured control.

\subsubsection{Ulcer index}

Oral administration of ethanol produces characteristic lesions in the glandular portion of the stomach in mice (33.75 mm). These lesions were significantly reduced in mice treated with the aqueous extract $(14.1 \mathrm{~mm})$ at the tested dose (400 $\mathrm{mg} / \mathrm{kg}$ ) with a percentage of protection (91\%) (Table 3). The results of the present study are comparable to those of 26 
Table 3: Effects of A. absinthium aqueous extract on ethanol-induced acute gastric ulcer

\begin{tabular}{|l|c|c|l|c|}
\hline Mice & $\mathrm{N}^{\circ}$ & $\begin{array}{c}\mathrm{D} \\
(\mathrm{mg} / \mathrm{kg})\end{array}$ & $\begin{array}{l}\mathrm{U} \text { I } \\
(\mathrm{mm})\end{array}$ & Protection (\%) \\
\hline Control & 5 & - & 33.75 & - \\
\hline Extract & 5 & 400 & 14.1 & 91 \\
\hline
\end{tabular}

\section{CONCLUSION}

This study contributed to the knowledge of the antioxidant and antiulcer potentials of Artemisia absinthium. These activities are partially linked to the presence of phenolic compounds. The aqueous extract of Artemisia absinthium has a considerable content of total phenolic compounds which can contribute to the field of functional foods and gave a good gastro-protective effect. It would be interesting to elucidate the mechanisms by which the aqueous extract of Artemisia absinthium exerts its effects.

\section{ACKNOWLEDGMENTS}

This work was supported by the Algerian Ministry of Higher Education and Scientific Research (MESRS). We express our gratitude to these organizations.

\section{REFERENCES}

1.Raita M.S., Iconaru S.L., Groza A., Cimpeanu C., Predoi G., Ghegoiu L. , Badea M. L., Chifiriuc M.C., Marutescu L., Trusca R., Furnaris C. F. , Turculet C.S. , Enache D.V. and Predoi D. Multifunctional Hydroxyapatite Coated with Arthemisia absinthium Composites; Molecules 2020; 25:413.

2. Abad M. J., Bedoya L. M., Apaza L. and Bermejo P. The Artemisia L. Genus: A Review of Bioactive Essential Oils, Molecules 2012; 17:2542-2566

3.Moacă E.A., Pavel I.Z., Danciu C., Crăiniceanu Z., Minda D., Ardelean F., Antal D.S., Ghiulai R., Cioca A., Derban M., Simu S., Chioibas R. , Szuhanek C., and Dehelean C.A. Romanian Wormwood (Artemisia absinthium L.): Physicochemical and Nutraceutical Screenin, Molecules 2019; 24:3087.

4. Mohammad A. ,Ahmadzadeh S.T., Ameri A.A., Imani M., Golmakani E., and Kamali H. Seasonal variation in the chemical composition, antioxidant activity, and total phenolic content of Artemisia absinthium essential oils, Pharmacognosy Res. 2015; 7(4):329-334.

5. Tan B.L., Norhaizan M.E., and Liew W.P.P. Nutrients and Oxidative Stress: Friend or Foe, Oxidative Medicine and Cellular Longevity, 2018; 9719584, p 24

6. Steller J.G., Alberts J.R. and. Ronca A.E. Oxidative Stress as Cause, Consequence, or Biomarker of Altered Female Reproduction and Development in the Space Environment, Int. J. Mol. Sci, 2018; 19:3729.

7.Loucif1 K., Benabdallah H, Benchikh F., Mehlous S., Ben Souici C., Amira S. Total Phenolic Contents, DPPH Radical Scavenging and $\beta$-Carotene Bleaching Activities of Aqueous Extract from Ammoides atlantica, Journal of Drug Delivery \& Therapeutics. 2020; 10(3-s):196-198.

8. Farzaei M.H., Abdollahi M. Role of dietary polyphenols in the management of peptic ulcer, World J Gastroentero,l 2015 June 7; 21(21):6499-6517.

9. Ferreira A., Proença C., Serralheiro M.L., and Araújo M.E. The in vitro screening for acetyl cholinesterase inhibition and antioxidant activity of medicinal plants from Portugal, J Ethnopharmacol, 2006; 108:31-37.

10. Li H.B., Wong C.C., Cheng K.W., Chen F. Antioxidant properties in vitro and total phenolic contents in methanol extracts from medicinal plants. LWT - Food Sci. Technol. (Leben smittelWissenschaft -Technol.) 2008; 41(3):385-390.

11. Bahorun T., Gressier B., Trotin F., Brunete C., Dine T., Vasseur J., Luyckx M.,Cazin M., Pinkas M. Oxygen species scavenging activity of phenolic extract from Hawthorn fresh plant organs and pharmaceutical preparations; Arzneim Forsch/Drug Res. 1996; 46:1086-1089.

12. Burits M., Bucar F. Antioxidant activity of Nigella sativa essential oil. Phytother Res 2000; 14:323-28.

13. Benchikh F. Pharmacological Effects of Myrtus Communis L. on the Gastrointestinal Tract of Rats and Mice. Ph.D. Thesis, Department of Biology and Animal Physiology, Faculté des Sciences de la Nature et de la Vie, Université Ferhat Abbas Sétif 1, Setif, Algeria, 2018.

14.Craciunescu O, Constantin D, Gaspar A, Toma L, Utoiu E, Moldovan L. Evaluation of antioxidant and cytoprotective activities of Arnica montana L. and Artemisia absinthium L. ethanolic extracts. Chem Centr J, 2012; 6:97.

15. Bora K.S, and Sharma A. Evaluation of antioxidant and freeradical scavenging potential of Artemisia absinthium. Pharmaceutical Biology, 2011; 49(12):1216-1223.

16. Dane Y, Mouhouche F, Canela-Garayoa R, · Delpino-Rius A. Phytochemical Analysis of Methanolic Extracts of Artemisia absinthium L. 1753 (Asteraceae), Juniperus phoenicea L., and Tetraclinis articulata (Vahl) Mast, 1892 (Cupressaceae) and evaluation of their biological activity for stored grain protection. Arab J Sci Eng, 2015; 41(6):2147-2158.

17. Sidaoui F., Igueld S.B., Yemmen M., Farouk M., Barth D., TrabelsiAyadi M., Cherif J.K. Chemical and functional characterization of Tunisian Artemisia absinthium volatiles and non- volatile extracts obtained by supercritical fluid procedure. Inter J Pharm Clin Res, 2016; 8(8):1178- 1185.

18. Lacroix S., Badoux J. K., Scott-Boyer M.P. Parolo S., Matone A., Priami C., Morine M.J., Kaput J. \& Moco S. A computationally driven analysis of the polyphenol-protein interactome, Scientific Reports; 2018, 8:2232.

19. Bo C.D., Bernardi S., Marino M., Porrini M., Tucci M., S., Cherubini A., Carrieri B., Kirkup B., Kroon P., Zamora-Ros R., Liberona N. H., Lacueva C. A., and Riso P. Systematic Review on Polyphenol Intake and Health Outcomes: Is there Sufficient Evidence to Define a Health-Promoting Polyphenol-Rich Dietary Pattern?, Nutrients, 2019; 11(6):1355.

20. Li H.B., Wong C.C., Cheng K.W., Chen F. Antioxidant properties in vitro and total phenolic contents in methanol extracts from medicinal plants. LWT - Food Sci. Technol. (Leben smittelWissenschaft -Technol.) 2008; 41(3):385-390.

21. Lee KW, Kim YJ, Lee H, and Lee CY, Cocoa Has More Phenolic Phytochemicals and a Higher Antioxidant Capacity than Teas and Red Wine. J. Agric. Food Chem, 2003; 51:7292-7295.

22. Al Jahid A., Essabaq S., Elamrani A., Blaghen M., and Jamal Eddine J. Chemical Composition, Antimicrobial and Antioxidant Activities of the Essential Oil and the Hydro-alcoholic Extract of Artemisia campestris L. Leaves from Southeastern Morocco. Journal of Biologically Active Products from Nature TBAP, 2016; $6(5 \& 6): 393-405$.

23. Oyaizu M. Studies on products of browning reactions: antioxidative activities of products of browning reaction prepared from glucosamine. Japanese Journal of Nutrition, 1986; 44:307-315.

24. Soares J.R., Dins T.C.P., Cunha, A.P., Almeida, LM, Antioxidant activity of some extracts of Thymus zygis. Free Radical Research, 1997; 26:469.

25. Mahmoudi M., Ebrahimzadeh M.A., Ansaroudi F., Nabavi S. F.and Nabavi S.M., Antidepressant and antioxidant activities of Artemisia absinthium L. at flowering stage African Journal of Biotechnology, 2009; 8(24):7170-7175, 15.

26. Shafi N., Khan G.A., Ghauri E.G. Antiulcer effect of Artemisia absinthium L. in rats. Pak. J. Sci Ind Res, 2004; 47(2):130-134. 